\title{
Poetic Consciousness in Pedagogy: An Inquiry of Contemplation and Conversation
}

\author{
Sean Wiebe \\ University of Prince Edward Island \\ Indrani Margolin \\ University of Northern British Columbia
}

\section{Author Note}

We wish to thank the anonymous reviewers who were helpful in suggesting ways to present this text more conversationally.

\begin{abstract}
In this paper we consider the kinds of pedagogical engagements a poetic consciousness might invoke. When we reflect on what it might mean to be poetically conscious in moments of teaching, learning, and connecting, what emerges is the possibility of integrating the classroom experience with the everyday of life; such poetically conscious teaching would make connections to the larger web of a person's experience in the world. To inquire into this possibility, we share our contemplations on our scholarly and personal experiences with poetry, presenting it here as a dis(e)ruptive text in order to invite aesthetic modes of being within the interplay of language and self. Our conversations have evolved over 3 years and have created this in-between space of active disclosure, where, we argue, poetry has offered dis(e)ruptions that celebrate the variations we inhabit in our bodies, personalities, and creative works.
\end{abstract}

Keywords: Poetic consciousness; pedagogy; contemplation; conversation; dis(e)ruptive text 


\section{Poetic Consciousness in Pedagogy: An Inquiry of Contemplation and Conversation Becoming Conscious Of and Conscious To Poetry}

My journey with poetry began as a child. My mother loved the cards I made her. No matter what colour I used, what pictures I drew, or what words I wrote, she always made it seem like the most beautiful artwork in the world.

I see nothing out of place or time

Over time, my writing evolved into poetic renderings of care. I co-wrote my first formal poem for a Grade 6 assignment, entitled, "What is Life?" A deep sense of pride lodged itself in my belly for composing rhythm and rhyme. Some years later in Grade 12, my English teacher, Mrs. G, taught us to use metaphor and symbol with language. She wrote "great use of metaphor" on my final creative writing assignment. I remember reading what I had written over and over again and for the first time, thinking, "Wow, I can write!”

I see nothing

out of place or time

At age 17, poetry opened up a new space of possibility for me to write an alternative script of my life, one where I starred as a fierce warrior rather than a powerless victim. I was sexually abused as a child and decided to take the family friend/child molester to court. I had just completed a 1.5 year court trial process. Unfortunately, rather than the retribution and justice I had hoped for, the Supreme Court judge ruled not guilty. I felt re-victimized and horrified that this verdict perpetuated the continuation of sexual abuse to other girls. Everyone told me to "move on." I could not. Poetry was my only solace. The first months of journal writing were filled with swearing and vulgarity, but gradually over time other words and metaphors began to fill the pages.

Through the act of writing, I was freed from carrying the heavy weight of my pain. To see my hurt and anguish, as words metamorphosed into imagery, enlarged my identity beyond being a victim of abuse. That writing process expelled the shame, confusion, and self-doubt I felt.

What kinds of pedagogical engagements

does a poetic consciousness invoke?

\section{The Life and Span of Poetry}

In this paper, we share our contemplations on poetic consciousness. We share the kinds of engagement it has invoked throughout the web of our experiences.

What has it fostered?

What has it sustained?

Our scholarly/artistic processes have been necessarily, simultaneously personal and pedagogical. We've conceptualized; we've explored; we've woven-both narratively and poetically - the transformative insights that illuminate, interrogate, and console our ways of being in relation with ourselves-our students-our partners-our many others within and without our web of experience.

One teacher in particular breathed creative life into me and transformed my writing. He set me on a life-long journey to still my mind through meditation and consciously imagine the life I desire as if it were already mine (Sen, 2005). At age 18, a new wonder flooded my consciousness. From that serene stillness, the poetic flowed. Throughout my 20s, I traversed 
between rhythmic hard-hitting, spoken-word poetry that reflected the daily injustices I encountered, and free-flowing poetry about the wonder and mystery of the universe I was experiencing through meditation. Eventually, the free flow-er took over. Imbibed with a glimpse of human and cosmic connection, I began to practice writing about what I wanted to be and how I wanted to feel. I wrote this poetic instruction to myself:

Waste not your time in things that fade away.

Instead, dwell in the silence of which celestial sound arises,

Where your being can be freed and you may understand the mysteries of the universe.

The mind holds you captive in pettiness.

So you never see or feel the Infinitude of life.

Awake, O sister.

Let the demons be.

Come with me to swim in the sea of Love.

As time passed, poetry continued to fuel and flourish in my academic life. In a doctoral program of holistic and aesthetic education, empowering mentors came into my web of experience. Many, such as David Booth, Mary Beattie, Jack Miller, Lynn Fels, Celeste Snowber, and Linda Cameron, invited me to draw my dissertation from my own passions and experiences.

\section{Re/presenting Poetry as Contemplation/Conversation}

Always the sense that I have assembled myself from whatever stray words fall...

(Ramspeck, 2011, n.p.)

In the field of poetic inquiry, much of the work has considered how poetry can be employed to enrich our understanding of human experience (Prendegast, Leggo, \& Sameshima, 2009). Our method of contemplation and conversation advances that aim through our consideration of the particular kinds of engagement poetic consciousness invokes. Our conversations have taken place over 3 years, and over this time our text constructions have slowly emerged as we contemplated the "who" of who we have been becoming within the contexts of our disclosures. Our method of conversation has attended carefully to the in-between spaces of our memories, noting the many gaps between what is remembered and not remembered, what is shared and not shared, what is written and not written in the formal text, and what remains and what changes in the poetic re/presentation (MacDonald \& Wiebe, 2012). Presenting poetic inquiry as a conversational text, thus, becomes a tactic to resist overly determined and systematic conceptions of the theories, processes, and methods that have informed and guided the inquiry (Wiebe \& Guiney Yallop, 2010; Lund \& Veinotte, 2010). Leggo (2007) emphasizes how the "personal, pedagogical, narrative, ruminative, and hermeneutic" (p. 191) influence his poetic research, and how these can foster "lively dialogue" in the art of researching our lives (p. 191). Similarly, Sameshima (2009), following Levinas’s (1981) work on responsibility to others as part of being, values "ethical dialogue which welcomes critical discussion” (p. 11). Finding wisdom in such scholarly work, through contemplation and conversation, we have explored our teaching, learning, and connecting experiences of being conscious of and to poetry-

$O$, precious words Arise from the everflowing poetic. 
As a lover's glance

You enchant!

- giving particular attention to our ways of being in relation with ourselves and ourothers - whether they be within or without, whether they are partners, parents, students, lovers, scholars, or children.

As already illustrated in the opening narrative, we understand dialogue as more than "you speak," then "I speak," and repeat. Such a linear model, which often emphasizes a Hegelian synthesis, does not account for how dialogue also enables self-disclosure and discovery. Nor does such a linear approach account for notions of a dialogical self (Hermans \& Kempen, 1993), where various Is speak from different subjective positions within the self. It is our hope that even in this text-privileged text our conversational voices can be heard in our poetic play with alignment, paragraphing, and italics. We feel that our decision to provide few textual signals to help with hearing our separate voices leaves important textual openings to entice readerly/writerly ontological echoes which might be heard as reverberations throughout our work (Springgay, Irwin, \& Kind, 2005).

As seekers set out, always, the black unknown appears. They brace themselves for its storm, and lean further into fear than they had before, this lights the fire, illuminates new terrain.

The connection of poetic inquiry to conversation creates what we are calling a dis(e)ruptive text. A dis(e)ruptive text emerges when the subjected language of our conversation (Lacan, 1977, trans. 1966) and the sel(f)ves that we are disclosing remain fluid, dynamic, and unfixed (Butler, 1990), always meaning more than what can be contained through concepts, which cannot be (but normally are) exchanged at face value. A dis(e)ruptive text is an aesthetic text because it attends to the artfulness of one's agency in performing the fluid, unfixed self. Thus attuned self-making and the language play of that making, our conversations in poetic inquiry are aesthetic and ideally suited to troubling the normative sine qua non of communication exchange that leads to (token) understandings.

Close attention to the aesthetics of our conversations is part of our reasoning for re/presenting our contemplations...as poetry. Conceptually, we imagine our work in this ellipsis between contemplation and poetry, at the threshold of their meeting, and this conversation about our work lingers there, stepping neither fully into the domain of one nor the other. To have "not stepped" recognizes the value of contemplation, of exploration, and aesthetic disclosure of the sel(f)ves through poetry. Our conversations have been full of movement, and we wish to suggest that our process has not unfolded linearly as steps but has spiralled horizontally, vertically, and diagonally as our inquiry took flight.

The instability often associated with conversational discourse does not need to be experienced as a loss of certainty or a reduction of agency. Todd (2011) explains that uniqueness emerges "in the in-between space with other human beings; it reveals itself in speech and action" (p. 105). Further, quoting Arendt, Todd notes the possibility for "sheer human togetherness" which is "actively disclosed" when human beings are encountering each other (p. 105). Our conversations about our experiences with poetry have created this inbetween space of active disclosure, and we suggest that teachers and scholars, through their 
own lively and ethical conversations with one another, can offer dis(e)ruption to provoke greater humanity toward uniqueness, that ever-shifting process of becoming one's sel(f)ves. This kind of conversation, in its openness to exploring what is not known, is emancipatory, leaving each of us the "intellectual room" (Ruitenberg, 2011, p. 211), to seek, question, provoke, and dis(e)rupt one another in our aesthetic and critical engagement that is conversation.

The poetic slips the mind into an imaginative state of play

\section{Moments of Dis(e)ruption: Recognizing Poetry in/as Pedagogy}

In a class I taught, graduate arts education student and poet, Colleen Erikson (2011) was a vital dis(e)rupter of the classroom space. She writes:

\section{Ineffable}

Rail against the yellow leaves

Curse the summer's end

Barely healed by the Salmon Moon

The encroaching night reopens your torn soul

Cry the blue sky cloudy

Pound the earth with your heartache

The rain distilled shall nourish your starving soul

Earth's affection restores your each step as you journey back home

As Norman (2009) notes, in poetry words become freed from censored reality, telling more of the story. The poet can explore and glimpse heights of rapture, depths of despair, or any degree of varying intensity of emotion in-between through nonlinear word play and sequencing. Poetry is a language for the whole being-body, mind, and soul.

O what the songs didn't tell us! (Zaqtan, 2011, n.p.)

For me, poetry was not immediately recognizable as pedagogy; it was more traditionally a literary form, something I wrote and sent into the world. Leggo's (2005) notion of living poetically was influential in beginning my thinking of what it might mean to genuinely teach poetically. Daily I started to wonder what teaching poetically looked like and felt like. What started to emerge was a permission to explore, to speak out, and to risk saying what is normally scribbled out in a private journal. I can't claim that poetry creates a safe classroom for everyone, but it does invite and give permission, and for those who move into that space, a poetic pedagogy honours and celebrates the words that come out of our lived experience.

\section{Being Still (and still being) in Conversation: The Misnomer of a Completed Text}

\section{Fulfilled thus far, why do I need to see the end?}

Even as we near completion of this conversation (for now), we recognize the misnomer of "complete." We have not covered all that we wished to and our conversation continues throughout (and beyond) the revisions of the text. The text will have a resemblance to completion: It will have recognizable margins and boundaries; it will have its summaries, abstracts, and keywords; and it will be archived as a thing and easily perused (or dismissed) based on the thing it appears to be. We liken this resemblance to a photograph, to a map, and 
to the concepts that words themselves point to. Each of these "snapshots" come into being and prompt inquiry and understanding, as metonymically one thing appears to be symbolic of something conceptually more original. The rich possibilities of discovery, we suggest, are in the gap between the thing and the origin it appears to indicate.

\section{Circling Back to Consciousness: A Theory of Dis(e)Ruption}

\section{Conversation continues revising}

the text

resembling

the self,

the unknown haunts

of a stranger familiar

with the night.

Part of our conversation has been contemplation of our conversation. At times, it seemed as if we understood each other along the way, but our confidence in that understanding needed to be disrupted. Knowing how easily meaning slips and becomes something else, we re/read (wrote) and re/listened (spoke). And what happened? New understandings erupted. These second understandings - or eruptions - were not of a higher order, nor were they more refined. They did not add clarity, nor did they cancel out anything that came before. What emerged was a sense that each moment of looking back was, additionally, a new moment of understanding. This, we believe, is what often happens in poetry and conversation, and it was not troubling to us in that "sense" of panic or emergency. Newly troubled-in that sense of joy when encountering a difficulty worthy of sustained attention-we simply gave ourselves over to dis(e)ruption.

Poetic dis(e)ruption is lively and it is ethical as it seeks to understand the context and nature of disclosure. Todd (2011) puts forward a strong case for why understanding the uniqueness of being is so rarely part of traditional educational activity. Attending carefully to the work of Arendt and Cavarero, she argues for deeper understandings of the specific context of conversational exchange. In practice, says Todd (2011), "diversity is shorthand for naming” (p. 103) differences, and thus, "cultural diversity is frequently synonymous with a view of individuals as the aggregate of their cultural attributes” (p. 102). As already noted, the trouble with naming and shorthand is that the ease of communicative exchange prevents us from understanding the genuine differences between individuals. Todd exposes the "lip service" paid to personal difference (p. 103) and notes the tendency for organizations to simply "handle" diversity rather than seek to understand being and becoming (p. 103). Todd is critical of constructs, which foreground dialogue as a "remedy" to difference (p. 103), arguing that what is of utmost importance is uniqueness of being. We agree. We see a poet's use of dialogue as lively, dis(e)ruptive, exploratory, and ethical, particularly since we have no outcomes in our engagement in this conversation.

Following Todd (2011), we note that our conversational text is not a "tool for remedying [our] competing worldviews, beliefs, knowledges, and positions” (p. 103). Through the language play in poetry, we find our differences can be received, acknowledged and enjoyed. Our consciousness in poetry helps create a consciousness through selfdisclosure in the (non)textual and cultural processes of constructing our lives. The poetic license in word play and concept shifting often elicits the presuppositions lurking just beneath 
the surface of a person, interaction, question, proposition, or policy. A poetic line of thinking can breathe spirited impulses into persons and blow the dust off mindless exchange.

Reborn a winged creature, twirling in this weightless world.

The received consciousness often exists beside the more standard or traditional text/self, whereby the poetic ploy is to play against the canonical-to contemplate-to contemplaycreating tension and alternate interpretation.

In poetic consciousness we fuse and refuse: we hold great respect for tradition, while at the same time questioning traditions again and again, reinterpreting them in their ever-changing contexts. Poetic consciousness often gives voice to that which has been silenced via erasure.
When I am in the real, I am creating. In touch with universal strength, I feel the milk of eternity flow from within (Margolin, 2009)-
From poets we hear feminine voices - we hear marginalized voices, minority voices, different voices. All permitted and invited to speak beside the position and disposition of the narrating voice.

\section{Poetically “Conscious” of Being in Relation to One Another}

Shortly after becoming a graduate teacher, which was not long after being a graduate student, I met Indrani and ever since we have been talking about what draws us to poetry in so many facets of our lives.

Poetry has helped me to reveal authentically the living inquiry I encountered with four courageous young women who embarked on a creative dance journey with me (Margolin, 2009). I invited them to employ the poetic as a way to imagine and envision their desired bodyself image and feelings. In response, Stacey, 16 years old, wrote:

\section{Imagining Anew Her Bodyself}

I would feel like no one's anything was better.

I would never feel inferior to anyone for no weird reason.

I would always be happy with my body.

I would never feel ashamed.

I would always be confident.

I would take on the world without second guessing.

Thank god for myself because my body is a blessing.

(Stacey, journal entry, April 20, 2005)

Leavy (2010) explains that heterosexual females struggle with accepting their bodily appearances and live with internalized dominant notions of femininity, which coincide with overall body dissatisfaction and competition with other heterosexual females who vie for the acquisition of a male partner. Stacey's daily experience of body assessment is marked against an external, unattainable standard. Her poetry addresses this widespread surveillance and control of others through the self, yet reaches through the comparison with other female bodies. Bordo (1993) ascertains that "preoccupation with fat, diet, and slenderness...may function as one of the most powerful normalizing strategies of our century...habituat[ing girls] to self-improvement and transformation in the service of these norms” (p. 186). 
Participation in poetry incites students not only to notice and attend to the dominant narratives internalized within them, but also to listen closely to the subjugated stories of their hearts. Poetry bestows form onto feeling.

While writing freely within the safe space of acceptance and empowerment begins as a fantasy, the practice of creating offers girls the experience of being a creator, with agency, rather than being powerless bystanders (Ellsworth, 1992). The freedom to think and feel what they desire in their image-worlds creates a bridge between known reality and not yet known imagination. There, they can dive into their inner desires and make the imaginary real (Fels, 2008). Change from bodyloathing to bodylove begins with a change in thought (Freedman, 1988). Writing crystallizes thought. With new thought comes new feeling, new perception, and ultimately a new making of self.

Play. Play. Cocoon me. Make me emerge as a butterfly,

Fluttering between each flower to suck out the nectar of life.

Stacey began her poem and each line, thereafter, with I would...However, by the end of the poem she is living the what if feeling of her imagining as a legitimate and valued presence in the now. She is transformed from what would be to what is. By attending to the pain, paradox, humour, and irony in our lived experiences, it is possible to consider how powerful emotions, oftentimes relegated to the personal and therefore insignificant, can and do have profound transformational effects on the ways we think about education and the school practices within it (Wright, 1997, p.81).

\section{Ins/citeful slipping moves us beyond}

\section{barren wastelands into lush jungles}

For me, once I named myself as a poet, and came to hear my own name when called as such, I was more inclined to disclose myself with students in living the learning. Contemplating this, I have become preoccupied lately with the ways proposed changes for improving teaching and learning become stifled in the systems, structures, and policies of the K-12 school culture.

What poetry does is to work outside the paradigms that stifle change: Poetry enlivens and invigorates my attention so that I'm attending to school in ways that are more likely to matter to students in their present circumstances.

The practice of poetry, the play of poetry, even what we might call the pose of poetry, proposes, (re)purposes, and (re)positions the culture of schooled thinking in multifaceted and artful ways. It is a means by which what has been taken for granted can be troubled and contested.

Poetry offers a respectful rendering of care and cracks open spaces where paradoxes can co-exist, bringing sacredness to live beside and within heart-wrenching data. A young woman gave me a piece of writing that outlined her experience of falling victim to dating violence. With poetry, I was able to honour her and release myself from my own feelings of rage and helplessness with regard to protecting girls from physical, emotional, and sexual assault.

\section{A Sumptuous Symphony of Voluptuous Variation}

An apple that is ready won't resist. Will come away

willingly, fall into the palm the way a lover does. (Ramspeck, 2011, n.p.) 
I thought I knew myself as a teacher, until I began to think Becoming conscious and write about how being a poet might change how I go as means to transcend about my pedagogy. Like Aoki (2005), I'm starting to wonder if rejection of difference there is a possibility of hearing pedagogy in a new key. and to generate Poetically, what might it mean more resilient identities to "hear" ourselves teaching? Through hearing, what and subjectivities might we be sharing of ourselves with students? Through within the multiplicity hearing, might we be more aware of those resonances that each inhabits. which arrive through tension? Might our humanness find a spaciousness, even a gracefulness in the classroom setting.

What if we were to attend and attune our teaching to the spirit and emotions of what we hear?

For us, hearing the culture of education is a particular kind of poetic consciousness: It is to deliberately pause... at taken-for-granted meanings. As poetic inquirers and as writers of poetry, we are often troubled with truth seeking capacities/tendencies: We hesitate when we hear sentences that contain the word "should" or "best" or "right." With respect to teaching, this hesitancy is developing because the language of best practices, of educational reform, and of school improvement creates recognizable emphases and patterns which seek to reduce creativity, experimentation, and difference. Responding to Fullen's (1993) call for attentiveness to the culture of education (p. 51), our poetic consciousness helps us rethink and (re)hear the clatter of what has been cultured and cluttered in educational cultures: and so it is that we linger in the relationships, practices, and ways of being in a school community.

Through writing poetry, through hearing poetry, particularly poetry which arises from reflecting on our teaching practice, I am learning to doubt most of what I used to know as certain.

We invite teachers and researchers alike to inquiries where students are encouraged to listen to the still small voice within them and to breathe life into that voice through poetic expression-

- linger with us in this thought - contemplate how this might transform what it is we come to know about teaching - what we might need to unlearn.

Knowing this possibility brings to life a healthy doubt of the kinds of narrating that bring too much coherence or consistency to the pedagogy that we are trying to understandand

-and the texts that represent them. I might be tempted to write, for example, that poetic reflection comes from deep within, a kind of wellspring of mind and spirit. But just as often, I find my poetry shallow, containing more mud than water, tasting perhaps like the chalk dust that once lined my hands and the lapels of a discount blazer. The poetic voice which doubts the seamless narrative does not need to be relegated to the margins as the voice of the critique-such a voice is also an authorial voice (Wiebe, 2007), one that tells many stories without privileging one story over another. Doubt can live in the poetic text by its re/presentation, its re/search into ways of being, and it is through these inter-textual performances that questions of meaning and purpose come to the fore. 
Rather than the typical ambivalence, ironic distance, or heartless telling of the doubter or skeptic, the many stories, which emerge from doubt, can offer engagement with the complex classroom experience. Isn't it this complexity that is so sumptuous and dangerous about being human, about teaching? Foregrounding doubt of the singular authority breathes a living curriculum into the authorized curriculum. Teaching poetically is just as likely to be un/authorized in the same way many postmodern writers acknowledge that to be un/authored is the claim of not having authorial power in teaching or in living, of not being able to create, to name, or to call to permanence (Wiebe, 2008).

For example, consider Morris's (2002) doubting of the educational truth of cognition: I cognate; therefore, I am. Without cognition, how could school exist?

There is a poetic way through this conundrum of cognition. Morris (2002) emphasizes consciousness, and in doing so, points to the mysteries of what it means to exist-and to teach-consciously. When we reflect on what it might mean to be poetically consciousness while in the classroom moments of teaching, learning, and connecting, what emerges is the hope to understand human beings in their myriad relations to one another-even if we are not always conscious of those relationships and the necessary preconditions for their consciousness.

\section{Grasping Voluptuous Variation}

Hands awaken with outstretched fingers.

Reaching, grasping, lifting, holding .

Affecting. Creating.

Intermingling consciousnesses. They oppose and balance.

Bodies awaken. Breath supported.

Fear subdues as they twist and flow.

Borders between bodies become fuzzy.

Consciousness shifts. Self protection melts.

Giving self to dance, to other.

The moment becomes recognizable, reverent to something ethereal yet palpable.

Melting and moving as one beneath voluptuous variation (Margolin, forthcoming).

Not unlike what Freire (1972) has described as conscientization, a poetic consciousness would be similarly charged with passion and the urgency of being as it means opening ourselves up to others - hearing otherness - and staying in a place of hearing.

What a poetic consciousness considers in its pedagogy is a bringing to consciousness the everyday web of relationships of one's belonging. Deeply conscious of what can be heard in this web of life/learning, teachers and students can stay open to multiple and shifting points of view, what so many have simply called love (Sameshima and Leggo, 2010).

Love, rather than being a distraction to teaching, can actually enliven it. With love, by love, and in love, students can find their own voice, trust the importance of themselves and their own words, and believe in their own contribution to a larger symphony. 


\title{
Concluding with the Wholeness of Love and Doubt, Light and Darkness
}

\author{
In the field of this body a great war goes forward, \\ against passion, anger, pride, and greed. \\ (excerpt from Kabir, 1915/1998, p. 85)
}

Returning again to the notion of dis(e)ruption, we find that doubt does leave us open to tiny provocations, what might be called poetic-pedagogical-provocations to a new kind of conscious teaching. Morris (2002) writes that consciousness is human. Eventually, doubt leads us back to being human: Poetry provokes this humanness in pedagogy. Not surprisingly, poetic consciousness connects us to an ongoing immersion in poetic living and being. Perhaps there is something in another's writing of a poem that we relate to as like-minded poetic journeyers. We are, it seems to me, searchers, and in the process of our seeking we come to know the world as poets. We know and doubt the world as poets, so we endeavour to read poetry, and to cite poetry as a way of understanding human experience in deeper ways. Poet Jack Gilbert is an example of that: In his poem, Poetry is a Kind of Lying, he helps us imagine the generative possibilities in the difficulty artists face in re/presenting human experience: "Degas said he didn't paint / what he saw, but what / would enable them to see / the thing he had” (Gilbert, 1982, lines 9-12).

The poetic demands the personal, the vulnerable, the magical, the relational aspects of scholarship and pedagogy. It invites the writer/reader/student/teacher to dwell in the spaces where there need not be light. Accepting the shadow within ourselves, that place that holds experiences that scare or hurt is a way to walk this earth in balance (Rogers, 1993). Becoming balanced with emotional content removes resistance and judgement from what one does not understand, and creates the possibility for acceptance and release. Poetic engagement has the capacity to crack open spaces for this process. Then, in the magic of the unknown, suspended between the creative and daily perception, we can transform the shadows, and transform ourselves toward wholeness (Rogers, 1993). For example,

The mystery of acceptance

In process

With consciousness

Revealing the mysterious beauty of grief

(Cat Siverton, 2011).

As writers/readers/students/teachers, we find the poetic invites, prods, and pushes us to this wholeness where we learn alongside one another. The poetic breathes life into the class and reaches beyond the classroom walls, for it causes each of us to inform and form ourselves with less closed definitions.

\section{Slipping into Consciousness}

$\begin{array}{ll}\begin{array}{l}\text { How far } \\ \text { down }\end{array} & \text { rises } \\ & \text { silence } \\ & \text { until } \\ \text { the } \\ \text { chatter }\end{array}$


of idle thought ceases

and I

submerge

into my

center

beneath the nervous belly of lovers,

not knowing which way to point their feet.

down there

somewhere

is a sweetness

the love I meet undulating between Andmerge into 


\section{References}

Aoki, T. (2005). Locating living pedagogy in teacher "research.” In W. Pinar and R. Irwin (Eds.), Curriculum in a new key (pp. 425-432). Mahwah, NJ: Lawrence Erlbaum.

Bordo, S. (1993). Unbearable weight: Feminism, western culture and the body. London, England: University of California Press Ltd.

Butler, J. (1990). Gender trouble: Feminism and the subversion of identity. New York: Routledge.

Ellsworth, E. (1992). Why doesn't this feel empowering? Working through the repressive myths of critical pedagogy. In C. Luke \& J. Gore (Eds.), Feminisms and critical pedagogy (pp. 90-119). New York: Routledge.

Erikson, C. (2011). Ineffable [unpublished poem].

Fels, L. (2008). Exploring curriculum: Performative inquiry, role drama, and learning. Vancouver, British Columbia, Canada: Pacific Educational Press.

Freedman, R. (1988). Bodylove: Learning to like our looks and ourselves. New York: Harper \& Row.

Freire, P. (1972). Pedagogy of the oppressed. Penguin Books, London, UK.

Fullen, M.G. (1993). Change forces: Probing the depths of educational reform. London: The Falmer Press.

Gilbert, J. (1982). Poetry is a kind of lying. In J. Gilbert, Monolithos. New York, NY: Knopf. Retrieved from: http://www.americanpoems.com/poets/Jack-Gilbert/9300

Hermans, H., \& Kempen, H. (1993). The dialogical self: Meaning and movement. San Diego: Academic Press.

Kabir (1998). Sur parkas, tanh rain kahan paiye [Poem] (Rabindranath Tagore, Trans.). In Songs of Kabir (pp. 84-86). York Beach, Maine: SAMUEL WEISER, INC.

Lacan, J. (1977). On a question preliminary to any possible treatment of psychosis. (Alan Sheridan, Trans). In Écrits: A selection, New York: Norton.

Leavy, P. (2010). Poetic bodies: Female body image, sexual identity and arts-based research. LEARNing Landscapes, 4(1), 175-185.

Leggo, C. (2005). The heart of pedagogy: On poetic knowing and living. Teachers and Teaching, 11(5), 439-455. doi: 10.1080/13450600500238436

Leggo, C. (2007). Tangled lines: The art of researching our lives. The Journal of Educational Thought, 41(2), 191-199.

Lund, D., \& Veinotte, C. (2010). Researching a social justice course in a charter school: A duoethnographic conversation. in education, 16(2). Retrieved from: http://www.ineducation.ca/article/researching-social-justice-course-char...

MacDonald, C., \& Wiebe, S. (2012). Methods in place: Learning to listen. Journal of the Canadian Association for Curriculum Studies, 9(2), 86-108.

Margolin, I. (2009). Beyond words: Girls bodyself (Unpublished doctoral dissertation). Ontario Institute for Studies in Education at the University of Toronto, Toronto, Ontario. 
Margolin, I. (in press). Expanding empathy through dance. In B. White \& T. Costantino (Eds.), Aesthetics, empathy, and education. New York, NY: Lang Publishing.

Morris, M. (2002). Ecological consciousness and curriculum. Journal of Curriculum Studies, 34(5), 571-587. doi: 10.1080/00220270110108187

Norman, R. (2009). Altered landscapes: Not the end of the journey. In S.G. Kouritzin, N.A.C. Piqamuel, \& R. Norman (Eds.) Qualitative research: Challenging the orthodoxies in standard academic discourse(s) (pp. 121-134). New York, NY: Routledge.

Prendergast, M., Leggo, C., \& Sameshima, P. (2009). Poetic inquiry: Vibrant voices in the social sciences. Rotterdam: Sense Publishers.

Ramspeck, D. (2011). Mechanical fireflies. New York, NY: Barrow Street Press. Retrieved from: http://poems.com/poem.php?date=15333

Rogers, N. (1993). The creative connection: Expressive arts as healing. Science and Behavior Books: Palo Alto, California.

Ruitenberg, C. (2011). Art, politics, and the pedagogical relation. Studies in the Philosophy of Education, 30(2), 211-223.

Sameshima, P. (2009). Stop teaching! Hosting an ethical responsibility through a pedagogy of parallax. Journal of Curriculum and Pedagogy, 6(1), 11-18.

Sameshima, P., \& Leggo, C. (2010). The poet‘s corpus in love: Passionate pedagogy. Journal of Curriculum Theorizing, 26(1), 65-81.

Sen, T. (2005). Ancient secrets of success 4 today's world. Toronto, Ontario, Canada: Omnilux Communications Inc.

Siverton, C. (2011). Untitled. [unpublished poem].

Springgay, S., Irwin, R., \& Kind, S. (2005). A/r/tography as living inquiry through art and text. Qualitative Inquiry, 11(6), 897-912.

Todd, S. (2011). Educating beyond cultural diversity: Redrawing the boundaries of a democratic plurality. Studies in Philosophy of Education, 30(2), 101-111.

Wiebe, Sean (2007). Un/authored autobiographical inquiry: Writing fiction for true truth. Annual Conference for the Association for the Advancement of American Curriculum Studies, Chicago.

Wiebe, S. (2008). What I meant to say about love: A poetic inquiry of un/authorized autobiography. Unpublished doctoral dissertation, UBC.

Wiebe, S., \& Guiney Yallop, J. (2010). Ways of being in teaching: Conversing paths to meaning. Canadian Journal of Education, 33(1), 177-198.

Wright, R. (2008). Research as quest: An autoethnographic exploration of embodied class, intellectual obsession, and the academy. Journal of Curriculum \& Pedagogy, 5(2), 69-94.

Zaqtan, G. (2011). Beirut, August 1982. (Fady Joudah, Trans.). The Massachusetts Review, Fall/Winter. Retrieved from: http://poems.com/poem.php?date=15336 